\title{
Home-based care practices and experiences influencing health- seeking behaviour among caregivers of children diagnosed with pneumonia in Endebess Sub-County, Kenya
}

\author{
Everlyne N Opuba ${ }^{1}$, Jane A Owenga ${ }^{2}$, Patrick O Onyango ${ }^{3}$ \\ 1 Division of Vaccines and Immunization, Ministry of Health, Trans-Nzoia County, ${ }^{2}$ Department of Public and Community Health and Development, \\ Jaramogi Oginga Odinga University of Science \& Technology, ${ }^{3}$ School of Physical and Biological Sciences, Maseno University \\ Keywords: home-based, health seeking, caregiver, pneumonia, kenya \\ https://doi.org/10.29392/001c.29573
}

Journal of Global Health Reports

Vol. 5, 2021

\begin{abstract}
Background
Pneumonia continues to be the second leading cause of both morbidity and mortality in children under five years in Kenya. In part, the high burden of the disease arises from delay and inappropriate health-seeking by caregivers. Caregivers delay seeking care at health facilities due to the administration of home-based remedies. Some home remedies may lead to a prolonged hospital stay and, in many cases, result in death. However, little is known about the home-based care practices for pneumonia. This study sought to examine predictors of home-based care practices and pneumonia experiences that influence health-seeking behaviour in Endebess Sub-County, Kenya.
\end{abstract}

\begin{abstract}
Methods
A cross-sectional study involving 273 caregivers accompanied by the qualitative study in the 24 health personnel was conducted from May to August, 2019. Questionnaires and key informant interview guides were used to collect data. Simple random sampling was used to select caregivers visiting the seven public health facilities in the sub-county. Quantitative data were analysed using SPSS Version 22 at a statistical significance of Ps 0.05 , whereas qualitative data were analysed by searching for emerging themes on home-based care practices and experiences shared by caregivers.

\section{Results}

Timely health-seeking behaviour was associated with available home care remedies $(\mathrm{P}=0.035)$ and knowledge of pneumonia symptoms $(\mathrm{P}<0.001)$. Caregivers with pneumonia experience from the house-hold $(\mathrm{P}<0.001$; odds ratio, $\mathrm{OR}=5.73,95 \%$ confidence interval, $\mathrm{CI}=2.787-11.799)$ and from other community members $(\mathrm{P}<0.001 ; \mathrm{OR}=6.49,95 \%$

$\mathrm{CI}=3.71-11.34)$ were more likely to visit the hospital on time relative to those without experience.
\end{abstract}

\section{Conclusions}

To improve health-seeking behaviour among caregivers, there is a need for health facility focal persons to incorporate health education and behaviour change communication interventions on pneumonia management at the community and hospital visits as caregivers seek antenatal and postnatal care services.

Pneumonia is the world's leading infectious killer of children, claiming the lives of more than 2,000 every day. ${ }^{1}$ Integrated Global Action Plan for Prevention and control of Pneumonia aims to end preventable childhood deaths due to pneumonia by 2025 and reducing pneumonia mortality in children <-5 years to fewer than 3 per 1000 live births. ${ }^{1}$ Globally, there are an estimated 150 million new cases of childhood pneumonia reported each year, and in 2015 pneumonia killed an estimated 922,000 children $<-5$ years worldwide. ${ }^{2}$ There is an estimated 61 million cases of childhood pneumonia, and these 11 to 20 million are life- threat- ening necessitating hospitalisation in developing countries. ${ }^{3}$ Pneumonia is the leading cause of mortality among children < -5years in developing countries and contributes to $18 \%$ of annual 7.6 million deaths in children $<-5$ years. ${ }^{3}$ Moreover, $95 \%$ of pneumonia deaths occur in sub-Saharan Africa(SSA). ${ }^{4}$ In Kenya, pneumonia is the second leading cause of death among children $<-5$ years and accounts for $16 \%$ of all child deaths. ${ }^{5}$ A report by Endebess Sub-county health information department revealed 3283(47.7\%) new cases of pneumonia in 2017 compared to $2842(41.3 \%)$ cases in $2016 .{ }^{6}$ This undermines sustainable development goal 3 
which is to ensure healthy lives and promote well-being for all at all ages. ${ }^{7}$

Integrated Management of Childhood Illness (IMCI) strategy was developed to reduce child mortality and morbidity. ${ }^{8}$ The strategy aimed at improving curative and preventive medical and behavioural interventions at hospitals, homes, and in the community. ${ }^{8}$ IMCI guidelines define danger signs which require a sick child to be managed quickly and referred after pre-referral treatment. ${ }^{9}$ General danger signs include: inability to feed, incessant vomiting, lethargy, unconsciousness and convulsions, while pneumonia specific danger signs include lower chest wall in-drawing and stridor. ${ }^{5}$ A systematic review of studies in developing countries Kenya included reported poor recognition of pediatric pneumonia by caregivers and represented a key factor to address to improve health care utilization. ${ }^{10,11}$

IMCI for pneumonia management also advocates for the administration of the first dose of an appropriate antibiotic before hospital attendance. ${ }^{8}$ Pneumonia guidelines recommend treatment using Amoxicillin dispersible tablets. ${ }^{12}$ It is unclear whether amoxicillin or broader-spectrum antibiotics are being used to treat community-acquired pneumonia in different WHO regions. ${ }^{13}$ Endebess Sub-county was of no exception in these regions. The medication cost ranges from KES 100 (USD 0.91) to KES 3,000 (USD 27.34), and most hospitals in Kenya can diagnose and treat pneumonia. ${ }^{14}$ However, timely and appropriate health-seeking is key to control pneumonia complications and deaths. World Health Organization, ${ }^{15}$ reported that only $58 \%$ of children with suspected pneumonia visit hospitals. Although treatment with effective antibiotics prevents pneumonia deaths, 2 out of 5 children visit a hospital in SSA. ${ }^{16}$ In Kenya, 67\% of children with pneumonia visit a hospital, with most caregivers practising late care-seeking. ${ }^{17}$ In Kenya, Trans-Nzoia county was categorised among 20 high-burden counties with poor child health outcomes, low coverage rates and poor health-seeking behaviour for child health services. ${ }^{18}$ This calls for investigation into factors contributing to poor outcomes.

Caregivers' actions are known to influence children's progression to illness or health. ${ }^{19}$ Therefore to promote the full participation of families in pneumonia management, there is need to understand caregiver's home-based care practices. For example, in Western Nepal pneumonia treatment is sought after home remedies have failed. ${ }^{20}$ Many caregivers in SSA try different home remedies and resort to hospital treatment after self-treatment efforts have failed or illness worsen. ${ }^{21,22}$ In Sierra Leone traditional medicine was significantly associated with not visiting a hospital for pneumonia treatment despite availability of free health care initiative. ${ }^{23}$ Despite evidence of the influence of homebased care practices on health-seeking in context of childhood pneumonia home support measures such as tepid sponging, child warming and breastfeeding remain unknown in contexts such as Endebess Sub-county.

Self-medication is another aspect of home-based care practice where by a person determines which medicine and the dosage to use for an ailment without consulting a qualified health care personnel. ${ }^{24}$ Abbey et al., ${ }^{21}$ identified selftreatment practiced by caregivers in Ghana using home remedies like Shea butter, honey and herbal medicine.
Some caregivers massaged children with Robb methylated ointment and hot water to relieve pain in the rib cage. ${ }^{25}$ Herbs in different forms were used to treat pediatric pneumonia; some were boiled or made into powder. ${ }^{26}$ In this study home-based care refers to any form of assistance given to sick children at places they live permanently with their parents or guardians before being taken to hospital for treatment.

Home-based care practice sometimes depends on sociodemographic characteristics of the caregiver. Financial resources, availability of time, support for household chores by family and community determined whether, when and from whom caregivers seek care. ${ }^{27}$ Therefore, it was important to include socio-demographic characteristics of caregivers to help health care workers share targeted health messages basing on needs of specific groups.

Regarding actions taken by caregivers after a previous experience of childhood illness, most caregivers offered drinks (49.6\%) and traditional herbs (45.3\%) while $31.7 \%$ gave antibiotics in Uganda. ${ }^{9}$ In Rwanda longer duration of illness was associated with formal health-seeking unfortunately most children died, among the 516 deaths of children $<-5$ years, 117 (22.7\%) did not seek care from a hospital but those with children previously admitted of childhood illness visited a hospital. ${ }^{28}$ The question is how previous pneumonia experience influenced health-seeking in Endebess Subcounty. In this study pneumonia experience refers to caregivers health care choices after previous history of pneumonia in the family. Health-seeking behaviour referred to time taken to seek for care. Prompt health-seeking was when care was sought within 24 hours or late care- seeking when care was sought after 24 hours. Therefore research on home-based care practices and pneumonia experiences will guide policy makers and public health scholars on evidence based interventions in management of pediatric pneumonia.

\section{METHODS}

\section{STUDY SETTING}

The study was conducted in Endebess Sub-county hospitals in Kenya from May to August, 2019. Endebess Sub-county has 130,747 people, 22,620 children $<-5$ years and 21,525 households with 14 community units and 7 public hospitals. ${ }^{6}$ According to patient files mean duration of admission due to paediatric pneumonia is 3 days (Min 1; Max 7). Oxygen therapy is only available in two hospitals namely Endebess Sub-county Hospital and Chepchoina Health Centre. In case of requirement for referral services one ambulance stationed at Endebess Sub-county Hospital serves the whole sub-county. This was a hospital based descriptive cross-sectional study of patients and qualitative study in the health personnel. It involved collecting quantitative and qualitative data from caregivers of children $<-5$ years with pneumonia and health personnel at Endebess Sub-county hospitals.

\section{STUDY POPULATION}

Study population consisted of health care workers in Endebess Sub-county hospitals. In addition, caregivers of chil- 
dren $<-5$ years with pneumonia seeking care at Endebess Sub-county hospitals were also included. The children were sourced from outpatient department and paediatric ward within Endebess Sub-county hospitals. The column on diagnosis in out-patient and in-patient register for children <5 years was used to identify children with pneumonia using a simple random sampling method. Numbers were written daily and those caregivers who picked even numbers and met eligibility criteria and gave consent were included in the study. The following day those who picked odd numbers were included. This was repeated until threshold sample size of 273 caregivers was reached. Caregivers of children <- 5 years were proportionately sampled for participation in the study from 7 hospitals depending on the percentage they were contributing to pneumonia cases to obtain a sample size of 273. For qualitative study in the health personnel, all 24 healthcare workers were included in the study as key informants.

\section{DATA COLLECTION PROCEDURES}

Primary data was collected using a questionnaire and key informant interview guide (KIIs). Eligible participants were interviewed at paediatric unit and outpatient department consultation rooms. Interviewers administered questionnaire and KIIs to consenting caregivers of children $<-5$ years with pneumonia and health workers respectively by face to face interviews. Interview responses were recorded by note taking.

\section{DATA MANAGEMENT AND ANALYSES}

Data collection tools were verified to ensure completeness. Quantitative data was coded, edited and cleaned to rule out errors. Qualitative data was organised in tables depending on emerging themes. Data was entered into an excel worksheet then verified to ensure subject identification numbers matched with the data in questionnaires. Finally quantitative data was imported into IBM SPSS Version 22. Statistical significance was determined using the chi-square test of independence and logistic regression at a statistical significance $\leqslant 0.05$. Logistic regression was used to determine how caregivers experiences of paediatric pneumonia was associated with prompt or late health-seeking behaviour. Qualitative data from KIIs was analysed by searching for emerging themes and presented in textual form.

\section{ETHICS CONSIDERATIONS}

Ethical approval was obtained from Ethical Review Board of University of Eastern Africa, Baraton (Ref No: UEAB/06/ 03/2019). Research permit was given by National Commission for Science, Technology and Innovation (NACOSTI/P/ 19/32404/29550). Letter of acceptance to carry out the study was granted by Medical Officer of Health of Endebess Subcounty.

\section{RESULTS}

\section{SOCIO-DEMOGRAPHIC CHARACTERISTICS OF RESPONDENTS}

Table 1 presents social-demographic characteristics of respondents.

\section{RELATIONSHIP BETWEEN SOCIO-DEMOGRAPHIC CHARACTERISTICS AND HEALTH SEEKING BEHAVIOUR}

There was a significant relationship between occupation $(P<0.001)$ and timely care-seeking, house-hold income $(P<0.001)$ and timely care-seeking, and level of education $(P=0.004)$ and time taken to visit a hospital. In the event of a child illness employed 14(66.7\%) caregivers prioritised timely health-seeking unlike farmers 62 (67.4\%) and caregivers without formal employment 48 (75\%) who took $>24$ hours to visit a hospital. In addition most 11(73.3\%) respondents with a household income of KES > 10,000 (USD >91.12) visited hospital early as compared to the 132 (70.6\%) with income bracket of KES <5,000 (USD <45.57). Caregivers with college education 14 (60.9\%) observed timely health-seeking as compared to primary levers 82 (77.4\%) who took time to visit a hospital (Table 2).

\section{ASSOCIATION BETWEEN HOME BASE CARE PRACTICES AND HEALTH-SEEKING BEHAVIOUR}

There was a significant association between knowledge of pneumonia symptoms $(P<0.001)$ and health-seeking behaviour, and available home remedies $(P=0.035)$ and health seeking behaviour (Table 3 ). Most caregivers 58(85.1\%) with knowledge deficit of pneumonia symptoms did not observe timely care-seeking. However, a few respondents 80 (39.8\%) who knew pneumonia symptoms visited a hospital on time. Moreover, more than half 33 (86.6\%) of respondents who administered herbal medication visited a hospital after 24 hours. Likewise caregivers who practiced self-medication 144 (64.6\%) did not visit a hospital on time. Self-medicated drugs attributed to caregivers not visiting a hospital on time were as follows: metronidazole 4 (100\%), Artemether Lumefantrine 11 (91.7\%), Co-trimoxazole 6 (75\%), Amoxicillin 34 (72.3\%) and unknown injection from a chemist 9 (69.2\%) as illustrated in Table 3. KIIs with health care workers revealed that all (100\%) caregivers delayed to take their children to hospital.

\section{RECOGNITION OF CLINICAL MANIFESTATION OF PNEUMONIA}

Table 3 shows that most respondents 206 (75.5\%) recognised that their children had pneumonia through clinical manifestation and some caregivers 67 (24.5\%) could not tell whether their children had pneumonia. Recognised clinical manifestations were: fast breathing 140 (68\%), hotness of the body 50 (24.3\%), cough $10(4.9 \%)$, chest wall in drawing 3 (1.5\%), and wheezing 3(1.5\%) as shown in (Figure 1). On the other hand, caregivers who could not diagnose pneumonia thought that their children had: malaria 62 (92.5\%), diarrheal illness 3 (4.5\%), traditional illness 1 (1.5\%) and anemia $1(1.5 \%)$ as illustrated in (Figure 2). 
Table 1. Socio-demographic characteristics of respondents.

\begin{tabular}{|c|c|c|c|}
\hline \multicolumn{2}{|c|}{ Characteristics } & \multirow{3}{*}{$\begin{array}{c}\text { Frequency }(\mathrm{n}=\mathbf{2 7 3}) \\
10 \\
202\end{array}$} & \multirow{2}{*}{$\begin{array}{c}\text { Percentage (\%) } \\
3.7\end{array}$} \\
\hline Gender of the caregiver & Male & & \\
\hline & Female & & 96.3 \\
\hline \multirow[t]{3}{*}{ Relationship to the child } & Father & 10 & 3.3 \\
\hline & Mother & 252 & 92.3 \\
\hline & Grandmother & 11 & 4.4 \\
\hline \multirow[t]{5}{*}{ Age of the caregiver } & $<18$ years & 4 & 1.5 \\
\hline & $18-24$ years & 64 & 23.4 \\
\hline & $25-34$ years & 115 & 42.1 \\
\hline & $35-44$ years & 77 & 28.2 \\
\hline & 45 and above & 13 & 4.8 \\
\hline \multirow[t]{2}{*}{ Marital status } & Single & 27 & 9.9 \\
\hline & Married & 246 & 90.1 \\
\hline \multirow[t]{5}{*}{ Age of the child } & $0-12$ months & 147 & 53.8 \\
\hline & 13-24 months & 47 & 17.2 \\
\hline & $25-36$ months & 42 & 15.4 \\
\hline & $37-48$ months & 19 & 7.0 \\
\hline & $49-59$ months & 18 & 6.6 \\
\hline \multirow[t]{4}{*}{ Occupation } & Employed & 21 & 7.7 \\
\hline & Business & 96 & 35.2 \\
\hline & Farmer & 93 & 34.0 \\
\hline & None & 63 & 23.1 \\
\hline \multirow[t]{3}{*}{ Household income } & USD $<45.57$ & 187 & 68.5 \\
\hline & USD 45.57-91.12 & 71 & 26.0 \\
\hline & USD >91.12 & 15 & 5.5 \\
\hline \multirow[t]{5}{*}{ Education level } & Never school & 5 & 1.8 \\
\hline & Primary & 106 & 38.8 \\
\hline & Secondary & 137 & 50.2 \\
\hline & College & 23 & 8.4 \\
\hline & university & 2 & 0.8 \\
\hline
\end{tabular}

\section{REASONS FOR DELAYED HEALTH-SEEKING}

Respondents attributed delayed health seeking to: taking time to observe the child for changes 77 (41.8\%), belief the illness was mild 21 (11.4\%), difficult terrain 20 (10.9\%), fear of being scolded at the hospital because of a parity of plus eight 20 (10.9\%), financial constrains 17 (9.2\%), waiting to finish drugs bought at chemist/shop 12 (6.5\%), long distance to hospital 7 (3.8\%), fear to be scolded at the hospital 3 (1.6\%), fear to be tested for HIV 3 (1.6\%), night time illness event $2(1.1 \%)$, assumed it was a normal cough 1 (0.5\%), no time had gone for work $1(0.5 \%)$ as shown in Table 4. In addition, key informants identified other causes of delayed health-seeking as; belief that care in private hospitals was better than public hospitals and use of over the counter drugs.

\section{PNEUMONIA EXPERIENCES AND HEALTH-SEEKING BEHAVIOUR}

Logistic regression determined relationship between pneumonia experience from the house-hold and from the community, and timely health-seeking behaviour. Logistic regression model had a good fit in the house-hold category $\left(\mathrm{X}^{2}\right.$ $=24.281, P<0.001)$ and in the community category $\left(\mathrm{X}^{2}\right.$ $=47.400, P<0.001)$. In addition, the model explained $11.9 \%$ variance in timely health-seeking behaviour and correctly classified $72.5 \%$ cases in the house-hold category. Thus, the odds of timely care seeking are 5.73 times greater among caregivers with pneumonia experience in the household $(P<0.001$; OR 5.73, 95\% CI 2.787-11.799) than those without

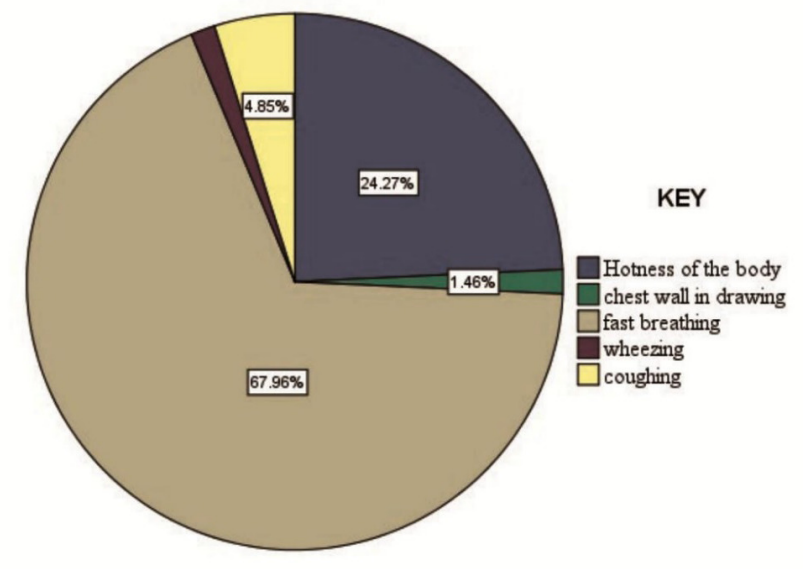

Figure 1. Recognition of clinical manifestation of pediatric pneumonia among the respondents

experience. Furthermore, the model explained $22.3 \%$ variance in timely care-seeking and correctly classified $72.8 \%$ cases in the community category. Caregivers with pneumonia experience from other community members were more likely to visit the hospital on time $(P<0.001 ; \mathrm{OR}=6.49,95 \%$ CI 3.71-11.34). 
Table 2. Relationship between social demographic aspects and health seeking behaviour.

\begin{tabular}{|c|c|c|c|c|c|c|}
\hline \multirow[t]{3}{*}{ Variable } & \multicolumn{4}{|c|}{ Time taken to seek for care } & \multirow{3}{*}{ Chi-square Test } & \multirow{3}{*}{ P-value (For major categories) } \\
\hline & \multicolumn{2}{|c|}{$\leq 24$ hours } & \multicolumn{2}{|c|}{$>24$ hours } & & \\
\hline & $\mathrm{n}$ & $\%$ & $\mathrm{n}$ & $\%$ & & \\
\hline $\begin{array}{l}\text { Occupation } \\
\text { I. Employed } \\
\text { II. Self- employed } \\
\text { Business } \\
\text { Farmer } \\
\text { None }\end{array}$ & $\begin{array}{l}14 \\
75 \\
29 \\
30 \\
16\end{array}$ & $\begin{array}{l}66.7 \\
29.8 \\
17.7 \\
32.6 \\
25\end{array}$ & $\begin{array}{l}7 \\
177 \\
67 \\
62 \\
48\end{array}$ & $\begin{array}{l}33.3 \\
70.2 \\
40.9 \\
67.4 \\
75\end{array}$ & 12.015 & 0.001 \\
\hline $\begin{array}{l}\text { House hold Income } \\
\text { I. USD }<91.12 \\
\text { USD }<45.57 \\
\text { USD 45.57-91.12 } \\
\text { II. USD >91.12 }\end{array}$ & $\begin{array}{l}78 \\
55 \\
23 \\
11\end{array}$ & $\begin{array}{l}30.2 \\
29.4 \\
32.4 \\
73.3\end{array}$ & $\begin{array}{l}180 \\
132 \\
48 \\
4\end{array}$ & $\begin{array}{l}69.8 \\
70.6 \\
67.6 \\
26.7\end{array}$ & 11.985 & 0.001 \\
\hline $\begin{array}{l}\text { Education Level } \\
\text { I. Low level } \\
\text { Never } \\
\text { Primary } \\
\text { II. High level } \\
\text { Secondary } \\
\text { College } \\
\text { University }\end{array}$ & $\begin{array}{l}25 \\
1 \\
24 \\
64 \\
49 \\
14 \\
1\end{array}$ & $\begin{array}{l}22.7 \\
25 \\
22.6 \\
39.3 \\
35.8 \\
60.9 \\
33.3\end{array}$ & $\begin{array}{l}85 \\
3 \\
82 \\
99 \\
88 \\
9 \\
2\end{array}$ & $\begin{array}{l}77.3 \\
75 \\
77.4 \\
60.7 \\
64.2 \\
39.1 \\
66.7\end{array}$ & 8.174 & 0.004 \\
\hline $\begin{array}{l}\text { Decision maker } \\
\text { I. Parents } \\
\text { Father } \\
\text { Mother } \\
\text { Father \& mother } \\
\text { II. Grand parents } \\
\text { Grandmother } \\
\text { Grandfather }\end{array}$ & $\begin{array}{l}85 \\
6 \\
64 \\
15 \\
5 \\
4 \\
1\end{array}$ & $\begin{array}{l}33.2 \\
46.2 \\
35.6 \\
23.8 \\
29.4 \\
26.7 \\
50\end{array}$ & $\begin{array}{l}171 \\
7 \\
116 \\
48 \\
12 \\
11 \\
1\end{array}$ & $\begin{array}{l}66.8 \\
53.8 \\
64.4 \\
76.2 \\
70.6 \\
73.3 \\
50\end{array}$ & 0.104 & 0.747 \\
\hline $\begin{array}{l}\text { Age of caregiver } \\
\text { I. }<35 \text { years } \\
<18 \text { years } \\
18-24 \text { years } \\
25-34 \text { years } \\
\text { II. } \geq 35 \text { years } \\
35-44 \text { years } \\
45 \& \text { above }\end{array}$ & $\begin{array}{l}64 \\
0 \\
18 \\
46 \\
25 \\
24 \\
1\end{array}$ & $\begin{array}{l}35 \\
0 \\
28.1 \\
40 \\
27.8 \\
31.2 \\
7.7\end{array}$ & $\begin{array}{l}119 \\
4 \\
46 \\
69 \\
65 \\
53 \\
12\end{array}$ & $\begin{array}{l}65 \\
100 \\
71.9 \\
60 \\
72.2 \\
68.8 \\
92.3\end{array}$ & 1.421 & 0.233 \\
\hline
\end{tabular}

\section{COMPARISON MANAGEMENT BEFORE AND AFTER \\ PNEUMONIA EXPERIENCE}

Following history taking among caregivers with a history of previous pediatric pneumonia experience in the household, it was evident that pneumonia management was different before the experience. Overall, 44 (54.3\%) respondents purchased drugs at the chemist, 17 (21\%) used left over drugs from previous illness episodes, some10 (12.3\%) caregivers visited a hospital, others 8 (9.9\%) borrowed drugs from a neighbor and a few 2 (2.5\%) treated their children with herbal medication. However, after history of pneumonia experience in the household caregivers managed their children differently. More than a half 54 (66.7\%) visited a hospital, 15 (18.5\%) bought drugs as what had been used previously when the child had pneumonia, 11 (13.6\%) went for an injection at the chemist then visited a hospital, and lastly $1(1.2 \%)$ started treatment early as compared to the initial management (Table 4).

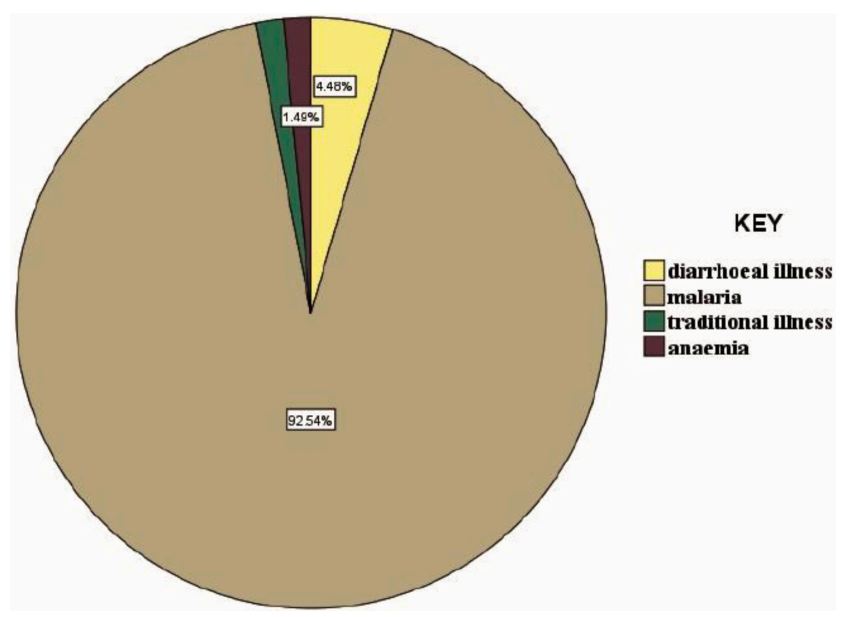

Figure 2. Distribution of respondents' thoughts of the diagnosis of their children. 
Table 3. Relationship between home-based care practices and health seeking behaviour.

\begin{tabular}{|c|c|c|c|c|c|}
\hline \multirow{2}{*}{ variable } & \multicolumn{3}{|c|}{ Time taken to seek for care } & \multirow{2}{*}{$\begin{array}{l}\text { Chi-square } \\
\text { Test }\end{array}$} & \multirow{2}{*}{$\begin{array}{l}\text { P-value (for major } \\
\text { categories) }\end{array}$} \\
\hline & $\begin{array}{l}\leq 24 \\
\text { hrs }\end{array}$ & $>24 \mathrm{hrs}$ & $\begin{array}{l}\text { Frequency } \\
\text { (\%) }\end{array}$ & & \\
\hline $\begin{array}{l}\text { Knowledge of the symptoms } \\
\text { Yes } \\
\text { No }\end{array}$ & $\begin{array}{c}80 \\
9\end{array}$ & $\begin{array}{c}126 \\
58\end{array}$ & $\begin{array}{l}206(75.5 \%) \\
67(24.5 \%)\end{array}$ & 14.847 & $<0.001$ \\
\hline $\begin{array}{l}\text { Available home remedies } \\
\text { I. Self-medication } \\
\text { Piriton } \\
\text { Flagyl } \\
\text { Amoxil } \\
\text { Multivitamin } \\
\text { Injection from chemist } \\
\text { Panadol } \\
\text { Cetirizine } \\
\text { Septrin } \\
\text { AL } \\
\text { II. Home remedies } \\
\text { Herbal } \\
\text { Salt \& water } \\
\text { Glucose \& water } \\
\text { Added warm clothes } \\
\text { Light fire } \\
\text { Warm water }\end{array}$ & $\begin{array}{c}79 \\
17 \\
0 \\
13 \\
1 \\
4 \\
37 \\
4 \\
2 \\
1 \\
10 \\
5 \\
1 \\
2 \\
1 \\
0 \\
1 \\
\end{array}$ & $\begin{array}{c}144 \\
28 \\
4 \\
34 \\
1 \\
9 \\
49 \\
2 \\
6 \\
11 \\
40 \\
33 \\
1 \\
2 \\
2 \\
1 \\
1 \\
\end{array}$ & 223(81.7\%) & 4.423 & 0.035 \\
\hline $\begin{array}{l}\text { Seeking treatment outside } \\
\text { home } \\
\text { Yes } \\
\text { No }\end{array}$ & $\begin{array}{l}88 \\
1\end{array}$ & $\begin{array}{l}184 \\
0\end{array}$ & $\begin{array}{l}272(99.6 \%) \\
1(0.4 \%)\end{array}$ & 2.075 & 0.150 \\
\hline
\end{tabular}

Table 4. Actions related to health-seeking among respondents.

\begin{tabular}{|c|c|c|}
\hline Actions related to health-seeking & Frequency & Percentage (\%) \\
\hline $\begin{array}{l}\text { Themes related to late care-seeking } \\
\text { Taking time to observe the child for changes } \\
\text { Belief that the illness was not severe } \\
\text { Difficult terrain } \\
\text { Fear of being scolded at the hospital because of parity of plus eight } \\
\text { Financial constrains } \\
\text { Waiting to finish drugs bought at the chemist/shop } \\
\text { Long distance to the health facility } \\
\text { Fear to be scolded at the hospital } \\
\text { Fear to be tested for HIV } \\
\text { Night time illness event } \\
\text { Thought that it was a normal cough } \\
\text { No time had gone to work }\end{array}$ & $\begin{array}{l}77 \\
21 \\
20 \\
20 \\
17 \\
12 \\
7 \\
3 \\
3 \\
2 \\
1 \\
1 \\
\end{array}$ & $\begin{array}{l}41.8 \\
11.4 \\
10.9 \\
10.9 \\
9.2 \\
6.5 \\
3.8 \\
1.6 \\
1.6 \\
1.1 \\
0.5 \\
0.5 \\
\end{array}$ \\
\hline $\begin{array}{l}\text { Management of the child before experience } \\
\text { Bought drugs at the chemist } \\
\text { Use of left over drugs from previous illness episodes } \\
\text { Took their children to hospital } \\
\text { Borrowed drugs from a neighbor } \\
\text { Administered herbal medication }\end{array}$ & $\begin{array}{l}44 \\
17 \\
10 \\
8 \\
2\end{array}$ & $\begin{array}{l}54.3 \\
21 \\
12.3 \\
9.9 \\
2.5\end{array}$ \\
\hline $\begin{array}{l}\text { Comparison management after experience } \\
\text { Took their children to hospital } \\
\text { Bought drugs as what had been used previously } \\
\text { Injection administered at a chemist then visited a hospital } \\
\text { Started treatment early }\end{array}$ & $\begin{array}{l}54 \\
15 \\
11 \\
1\end{array}$ & $\begin{array}{l}66.7 \\
18.5 \\
13.6 \\
1.2\end{array}$ \\
\hline
\end{tabular}




\section{RELATIONSHIP BETWEEN EXPERIENCE OF CHILD} SURVIVING OF PNEUMONIA AND HEALTH-SEEKING BEHAVIOUR

A Logistic regression determined relationship between experience of child surviving of pneumonia and timely healthseeking behaviour. Logistic regression model did not have a good fit $\left(\mathrm{X}^{2}=1.941, P=0.164\right)$. However, the model explained $2.4 \%$ variance in timely health care-seeking and correctly classified $56.5 \%$ cases. Thus, the odds of timely care-seeking is 2.92 times greater among caregivers with a child surviving pneumonia $(P=0.164$; OR $2.92,95 \%$ CI $0.577-14.746)$ than those without experience.

\section{DISCUSSION}

Results from this study revealed a significant relationship between administration of available home remedies, prior experience of pediatric pneumonia among caregivers and timely health care-seeking. Most caregivers administered herbal medicine, pharmaceutical products, warm salty water, glucose and water. A similar study in India revealed that the mother's first response to illness was the use of herbal medicine and visit to unqualified care providers. ${ }^{29}$ This may be explained by the existence of strong cultural belief in herbal medicine and shared decision making on the type of medicine to be prescribed by the unqualified care provider. It was also evident in South Africa that caregivers treated their sick children at home or visited clinics, private doctors, traditional healers, faith healers, and the hospital was the last resort. ${ }^{30}$ A similar study in Rwanda established that significant predictors of late health-seeking were the use of traditional healers, recognition of illness as mild, self-medication at home, special prayers by ministers of God before the first consultation at public institutions. ${ }^{31}$

Self-medication with pharmaceutical products based on previous prescriptions was evident in this study. Caregivers administered amoxicillin, metronidazole, co-trimoxazole, cetirizine, Chlorpheniramine maleate and paracetamol at home. This may be attributed to knowledge of pneumonia signs and the type of medication to be used in case of pneumonia or use of left-over drugs from previous illness episodes. The findings agree with a similar study in Ibadan, Nigeria, which identified high levels of antibiotic overuse with cough/cold. ${ }^{32}$ The findings have been reported in similar settings. ${ }^{33,34}$ Antibiotic overuse by self-medication risks worsening antibiotic resistance in future. It was unfortunate that some caregivers administered Artemether Lumefantrine without confirmation of malaria. This was due to in-ability to differentiate clinical manifestation of pneumonia and malaria by caregivers. However, they would take their children to the hospital if the condition persisted or symptoms were perceived to be severe.

The importance of pneumonia experience as an explanatory factor of health care-seeking cannot be ignored. Pneumonia experiences by caregivers positively influenced timely care-seeking, though some caregivers had no prior experience. After an experience of childhood pneumonia in the household, caregivers managed their children differently. Most caregivers visited a hospital on time, some bought drugs as lastly used when the child had pneumonia, others went for an injection at the chemist then visited a hospital, and others started treatment early compared to the initial management. There were no specific studies that revealed comparison in pneumonia management before and after the pneumonia experience. Therefore, it was important to share study findings.

Knowledge of pneumonia symptoms by caregivers was also linked to health care-seeking. Caregivers who recognised signs and symptoms of pneumonia took their children to the hospital on time. Most caregivers quickly recognised the hotness of the body and fast breathing as compared to the chest wall in drawing and wheezing. This was related to caregiver's knowledge deficit on the clinical manifestation of pneumonia. A similar study in Tanzania confirmed that most mothers rarely recognised fast breathing and chest indrawing as compared to cough or difficulty in breathing and fever as a manifestation of pneumonia. ${ }^{33}$

The socio-demographic characteristics linked to healthseeking behaviour were: type of occupation, level of education and household income. Results revealed that most employed caregivers and business people sought timely treatment for their sick children compared to those without formal employment. The reason being that they had money to cater for the financial needs required. In addition most caregivers whose household income was greater than KES 10,000 (USD 91.12) observed timely health-seeking. This agrees with Wambui et al., 35 whose study established determinants of health-seeking behaviour as occupation, household income and level of education. Most respondents with secondary and tertiary education sought timely treatment for their sick children compared to those with primary education and those who never went to school. This trend was associated with increased awareness through social media, television, newspapers, radio and linkage to informed colleagues and friends. This agrees with Wambui et al., ${ }^{35}$ who found that timely health-seeking was associated with tertiary and secondary education, and knowledge on danger signs of pneumonia. In contrast a few caregivers with university education did not adhere to timely health care-seeking as expected. This may be explained by improved telemedicine were caregivers access information on pneumonia management from friends and social media and therefore purchase over the counter drugs for their children.

Although caregiver age was not associated with timely health care-seeking, most caregivers aged 34years and above were delayed to visit a hospital. This is contrary to the role of experience in health care-seeking, which may be false to believe that mature caregivers make sound judgements when to seek care. A similar study in rural Tanzania revealed that caregivers aged 35 years and above practiced late health care-seeking for specific childhood illnesses. ${ }^{36}$ This may be attributed to prior infection experience and knowledge of medicine given at home by caregivers. Children of such caregivers are more likely to develop complications related to the disease, increasing child mortality or prolonged hospital stay.

Limitations of this study relate to the possibility of recall bias and a small number of health care workers. First, the possibility that caregivers forgot or omitted some information (recall bias) could not be excluded, although such bias may not have been substantial. Secondly, the sample 
size for key informants was 24 health care workers because the health facilities are understaffed and all health care workers were included in the study. Finally, because of a small number of health care personnel, the relationship between characteristics and health-seeking behaviour may not be strongly established. Despite the limitations, after data analysis it is evident that home-based care practices and pneumonia experiences influence health-seeking behaviour in Endebess Sub-county, Kenya.

\section{CONCLUSIONS}

This study reveals that caregivers of children with pneumonia delay health care-seeking due to various socio-demographic challenges, available home remedies and past experiences. Caregivers without formal employment and a household income of KES <5,000 (USD < 45.57) bore the largest brunt of late care-seeking. Knowledge deficit on clinical manifestation of pneumonia was evident among caregivers without formal education and this contributed to late care-seeking. Most caregivers easily identified fast breathing and hotness of the body, however chest wall indrawing and wheezing was rarely recognised as a manifestation of pneumonia by caregivers. Administration of home remedies and self-medication by caregivers also contributed to late care- seeking. However, knowledge of pneumonia symptoms, high education level, and availability of finances and experiences of pneumonia among caregivers was associated with timely health care- seeking.

There is a need for the health care system to develop mechanisms on how to improve health care- seeking among caregivers by ensuring an increase in coverage of government health insurance schemes among the vulnerable caregivers, sharing health messages on clinical manifestation, care and treatment of pneumonia during hospital visits by community health extension workers. Practices like selfmedication and administration of home remedies should be discouraged during micro-teaching. The study recommends that the government scale- up programs and diversify income generating activities to improve the economic status of community members. The government should also ensure $100 \%$ transition from primary to secondary education for caregivers to comprehend health dynamics in their environment and take appropriate health actions. The study recommends research on use of household as the unit of analysis since the household is not always homogenous. There is a need to research supportive care approaches for childhood pneumonia at the community level by community health volunteers and traditional medicine healers.

\section{ACKNOWLEDGEMENTS}

The authors acknowledge all caregivers of children for their cooperation .We would also wish to express our deepest gratitude to Endebess Sub County health management team for granting us permission to conduct the study in their area.

\section{DATA AVAILABILITY}

The data that was used to support the findings of this study is available from the corresponding author upon request.

\section{FUNDING}

None

\section{AUTHORSHIP CONTRIBUTIONS}

All authors contributed to conception and design of the work. ENO did analysis and interpretation of data. All authors contributed to drafting and revision of the manuscript. All authors approved the final manuscript.

\section{COMPETING INTERESTS}

The authors completed the Unified Competing Interest form at http://www.icmje.org/disclosure-of-interest/ (available upon request from the corresponding author), and declare no conflicts of interest.

\section{CORRESPONDING AUTHOR:}

Everlyne Narano Opuba, Master of Science in Epidemiology and Biostatistics. Division of Vaccines and Immunization Ministry of Health, Trans-Nzoia County Kitale, Kenya. Opubaeve@gmail.com

Submitted: August 08, 2021 GMT, Accepted: October 07, 2021 GMT 


\section{REFERENCES}

1. World Health Organization. Ending Preventable Child Deaths from Pneumonia and Diarrhoea by 2025. The integrated Global Action Plan for Pneumonia and Diarrhoea ( GAPPD ); 2013:1-61. http://apps.who.int/i ris/bitstream/10665/79200/1/9789241505239 eng.pdf

2. Noordam AC, Carvajal-Velez L, Sharkey AB, Young $\mathrm{M}$, Cals JWL. Care seeking behaviour for children with suspected pneumonia in countries in sub-Saharan Africa with high pneumonia mortality. PLOS ONE. 2015;10(2). doi:10.1371/journal.pone.0117919

3. Ferdous F, Dil Farzana F, Ahmed S, et al. Mothers' Perception and Healthcare Seeking Behavior of Pneumonia Children in Rural Bangladesh. ISRN Fam Med. Published online February 23, 2014:1-8. doi:10.1 $\underline{155 / 2014 / 690315}$

4. Lungu EA, Biesma R, Chirwa M, Darker C.

Healthcare seeking practices and barriers to accessing under-five child health services in urban slums in Malawi: A qualitative study. BMC Health Serv Res. 2016;16(1). doi:10.1186/s12913-016-1678-x

5. Health MOF. Basic Paediatric Protocols. Published online January 2016:25.

6. Health Information Department-Endebess subcounty

7. Group OW, Goals SD, Group OW, Goals SD, Goals D, Goals SD. Sustainable Development Goals and Targets. United Nations; 2015.

8. WHO IMCI. Integrated Management of Childhood Illness (IMCI) Chart Booklet. Distance Learn Course. Published online 2014.

9. Tuhebwe D, Tumushabe E, Leontsini E, Wanyenze R. Pneumonia among children under five in Uganda: Symptom recognition and actions taken by caretakers. Afr Health Sci. 2015;14(4):993. doi:10.431 4/ahs.v14i4.31

10. Geldsetzer P, Williams TC, Kirolos A, et al. The recognition of and care seeking behaviour for childhood illness in developing countries: A systematic review. PLOS ONE. 2014;9(4):e93427. doi:1 $\underline{0.1371 / \text { journal.pone.0093427 }}$

11. Ndu IK, Ekwochi U, Osuorah CDI, et al. Danger Signs of Childhood Pneumonia: Caregiver Awareness and Care Seeking Behavior in a Developing Country. Int J Pediatr. 2015;2015:1-7. doi:10.1155/2015/167261
12. Module O, Health FOR, Workers C. Integrated Management of Newborn \& Childhood Illness ( Imnci) Guidelines Updates.

13. Mathur S, Fuchs A, Bielicki J, Anker J.N. Van Den, Sharland M. Antibiotic Use for Community Acquired Pneumonia (CAP) in Neonates and Children: 2016 Evidence Update.; 2016.

14. Barasa EW, Ayieko P, Cleary S, English M. Out - of - pocket costs for paediatric admissions in district hospitals in Kenya. Trop Med Int Heal. 2012;17(8):958-961. doi:10.1111/j.1365-3156.2012.03 $\underline{029 . x}$

15. WHO | Care seeking for pneumonia. WHO. Published 2017. http://www.who.int/gho/child_healt h/prevention/pneumonia text/en/

16. Noordam AC, Sharkey AB, Hinssen P, Dinant G, Cals JWL. Association between caregivers' knowledge and care seeking behaviour for children with symptoms of pneumonia in six sub-Saharan African Countries. BMC Health Serv Res. 2017;17(1). doi:10.11 86/s12913-017-2060-3

17. Kenya National Bureau of Statistics (KNBS), ICF Macro. Kenya Demographic and Health Survey 2014. Heal (San Fr). Published online 2014:318-323.

18. Ministry of Health. GFF: Kenya Reproductive, Maternal, Newborn, Child and Adolescent Health (Rmncah) Investment Framework. Kenya Reprod, Matern, Newborn, Child Adolesc Heal; 2016.

19. Opwora AS, Laving AM, Nyabola LO, Olenja JM. Who is to blame? Perspectives of caregivers on barriers to accessing healthcare for the under-fives in Butere District, Western Kenya. BMC Public Health. 2011;11(1). doi:10.1186/1471-2458-11-272

20. Sreeramareddy CT, Shankar RP, Sreekumaran BV, Subba SH, Joshi HS, Ramachandran U. Care seeking behaviour for childhood illness- A questionnaire survey in western Nepal. BMC Int Health Hum Rights. 2006;6(1). doi:10.1186/1472-698x-6-7

21. Abbey M, Chinbuah MA, Gyapong M, Bartholomew LK, Van Den Borne B. Community perceptions and practices of treatment seeking for childhood pneumonia: A mixed methods study in a rural district, Ghana. BMC Public Health. 2016;16(1). $\underline{\mathrm{d}}$ oi:10.1186/s12889-016-3513-z 
22. Källander K, Hildenwall H, Waiswa P, Galiwango E, Petersona S, Pariyob G. Delayed care seeking for fatal pneumonia in children aged under five years in Uganda: A case-series study. Bull World Health Organ. 2008;86(5):332-338. doi:10.2471/blt.07.049353

23. Diaz T, George AS, Rao SR, et al. Healthcare seeking for diarrhoea, malaria and pneumonia among children in four poor rural districts in Sierra Leone in the context of free health care: Results of a crosssectional survey. BMC Public Health. 2013;13(1). doi:1 $\underline{0.1186 / 1471-2458-13-157}$

24. Pajuelo MJ, Anticona Huaynate C, Correa M, et al. Delays in seeking and receiving health care services for pneumonia in children under five in the Peruvian Amazon: A mixed-methods study on caregivers' perceptions. BMC Health Serv Res. 2018;18(1). doi:1 $\underline{0.1186 / \mathrm{s} 12913-018-2950-\mathrm{z}}$

25. Rutebemberwa E, Kallander K, Tomson G, Peterson S, Pariyo G. Determinants of delay in careseeking for febrile children in eastern Uganda. Trop Med Int Heal. 2009;14(4):472-479. doi:10.1111/j.136 5-3156.2009.02237.x

26. Hildenwall H, Nantanda R, Tumwine JK, et al. Care-seeking in the development of severe community acquired pneumonia in Ugandan children. Ann Trop Paediatr. 2009;29(4):281-289. doi:10.1179/0 $\underline{27249309 x 12547917869005}$

27. Aftab W, Shipton L, Rabbani F, et al. Exploring health care seeking knowledge, perceptions and practices for childhood diarrhea and pneumonia and their context in a rural Pakistani community. BMC Health Serv Res. 2018;18(1). doi:10.1186/s12913-01 8-2845-Z

28. Kagabo DM, Kirk CM, Bakundukize B, et al. Careseeking patterns among families that experienced under-five child mortality in rural Rwanda. PLOS ONE. 2018;13(1):e0190739. doi:10.1371/journal.pone.0190 $\underline{739}$
29. Mohanraj R, Kumar S, Jayakumar S, et al. Where do mothers take their children for pneumonia care? Findings from three Indian states. PLOS ONE. 2019;14(4):e0214331. doi:10.1371/journal.pone.0214 $\underline{331}$

30. Haskins L, Grant M, Phakathi S, Wilford A, Jama $\mathrm{N}$, Horwood C. Insights into health care seeking behaviour for children in communities in KwaZuluNatal, South Africa. African J Prim Heal Care Fam Med. 2017;9(1). doi:10.4102/phcfm.v9i1.1378

31. Umuhoza C, Karambizi AC, Tuyisenge L, Cartledge P. Caregiver delay in seeking healthcare during the acute phase of pediatric illness, Kigali, Rwanda. Pan Afr Med J. 2018;30. doi:10.11604/pamj.2018.30.160.15 $\underline{286}$

32. Kirolos A, Ayede AI, Williams LJ, et al. Care seeking behaviour by caregivers and aspects of quality of care for children under five with and without pneumonia in Ibadan, Nigeria. J Glob Health. 2018;8(2). doi:10.7189/jogh.08.020805

33. Muro F, Meta J, Renju J, et al. "It is good to take her early to the doctor" - mothers' understanding of childhood pneumonia symptoms and health care seeking in Kilimanjaro region, Tanzania. BMC Int Health Hum Rights. 2017;17(1). doi:10.1186/s12914-0 17-0135-1

34. Bham SQ, Saeed F, Shah MA. Knowledge, Attitude and Practice of mothers on acute respiratory infection in children under five years. Pak J Med Sci. 2016;32(6). doi:10.12669/pjms.326.10788

35. Wambui WM, Kimani S, Odhiambo E. Determinants of Health Seeking Behavior among Caregivers of Infants Admitted with Acute Childhood Illnesses at Kenyatta National Hospital, Nairobi, Kenya. Int J Pediatr. Published online December 16, 2018:1-11. doi:10.1155/2018/5190287

36. Kanté AM, Gutierrez HR, Larsen AM, et al. Childhood Illness Prevalence and Health Seeking Behavior Patterns in Rural Tanzania. BMC Public Health. 2015;15(1). doi:10.1186/s12889-015-2264-6 